\title{
Interactive comment on "Elucidating the ozone pollution in Yangtze River Delta region during the 2016 G20 summit for MICS-Asia III” by Zhi-zhen Ni et al.
}

\section{Anonymous Referee \#1}

Received and published: 16 November 2019

This paper attempts to understand the factors governing urban ozone (O3) pollution during the campaign of G20 summit held in 2016 in Hangzhou, China. The authors used the Weather Research Forecasting model with Chemistry (WRF-Chem) model to simulate the spatial and temporal ozone evolution in the Yangtze River Delta (YRD) region from 24 August to 06 September 2016. The authors conclude that the vertical diffusion and the enhanced local photochemical generation was responsible for the increase of surface ozone concentration in Hangzhou.

While this is an interesting case study, the motivation of the paper is not clear to me. 
responded to the tropical cyclone during their study period or [b] if they are interested in understanding whether emergency control measures put in place for the G20 meeting helped reduce ozone levels or not?

If their objective is [a], this study lacks novelty because it is now well understood that clear-sky stagnant conditions favor photochemical ozone formation and cloudy-skies suppress it. Thus, ozone variations reported and modeled before, during, and after the cyclone are expected and there is no new knowledge gained here.

If their objective is [b], the model experimental design is not appropriate. The authors did not modify their emission input to reflect emission control measures in their model simulations and no sensitivity experiment was performed to understand what would have happened in the absence of emergency emission control measures? There was no analysis of whether or not the observations at 96 sites violated the ozone standard during the G20 meeting?

The choice of Hangzhou as the analysis site is also not clear. Authors say that they selected the site based on evaluation but no evaluation metric was presented to justify their decision to focus on Hangzhou. Why not use all the observations from 96 sites in your analysis to get a regional picture?

In addition to these major concerns, below are some other specific concerns that the authors might find useful in their revision.

Section 2:3: Can you be a little more specific about the IPR here? Did you save the tendency terms before and after the call to each process is made in the code? For example, did you save ozone concentrations before and after the call the chemistry solver and used the difference in the process analysis?

Table S1: For some reason, the equations did not appear correctly in the Table. Please correct.

Printer-friendly version

Section 2.4: Are the observations from air quality monitoring network quality controlled 
or did you apply any quality control procedure to the measurements before using those for evaluation?

Line 255: Change "supply raw material" to "transport ozone precursors"

Figure 8 shows that horizontal advection contributes much larger to the ozone increase on most of the days but in the abstract the authors say "vertical diffusion and chemical production" are the main drivers. I did not understand how the authors concluded this in the abstract.

Interactive comment on Atmos. Chem. Phys. Discuss., https://doi.org/10.5194/acp-2019-634, 2019. 